\title{
Downscaling Essential Climate Variable (ECV) Soil Moisture using Multi-source Data from 2003 to 2010 in China
}

\author{
Hui-Lin Wang ${ }^{a}$, Ru An ${ }^{b^{*}}$, Jia-jun You ${ }^{b}$, Ying Wang ${ }^{c}$, Yuehong Chen ${ }^{b}$, Xiao-ji Shen ${ }^{b}$, Wei \\ Gao $^{\text {b }}$, Yi-nan Wang ${ }^{b}$, Yu Zhang ${ }^{b}$, Zhe Wang ${ }^{b}$, Jonathan Arthur Quaye-Ballard ${ }^{d}$ \\ ${ }^{a}$ Nanjing University, School of Geographic and Oceanographic Sciences, Nanjing, Jiangsu 210093, \\ P. R. China; \\ ${ }^{\mathrm{b}}$ Hohai University, School of Earth Sciences and Engineering, No. 8 Focheng West Road, Nanjing, \\ Jiangsu,211100, P. R. China; \\ ${ }^{c}$ University of Southampton, Department of Geography and Environment, Southampton, SO17 1BJ, UK; \\ ${ }^{\mathrm{d}}$ Kwame Nkrumah University of Science and Technology (KNUST), Department of Geomatic \\ Engineering, Kumasi, Ghana
}

\begin{abstract}
Soil moisture plays an important role in the water cycle within the surface ecosystem and it is the basic condition for the growth of plants. Currently, the spatial resolutions of most soil moisture data from remote sensing range from ten to several tens of $\mathrm{km}$, while those observed in situ and simulated for watershed hydrology, ecology, agriculture, weather, and drought research are generally less than $1 \mathrm{~km}$. Therefore, the existing coarse-resolution remotely sensed soil moisture data need to be downscaled. This paper proposes a universal and multi-temporal soil moisture downscaling method suitable for large areas. The datasets comprise land surface, brightness temperature, precipitation, and soil and topographic parameters from high-resolution data, and active/passive microwave remotely sensed Essential Climate Variable soil moisture (ECV_SM) data with a spatial resolution of $25 \mathrm{~km}$. Using this method, a total of 288 soil moisture maps of $1 \mathrm{~km}$ resolution from the first 10-day period of January 2003 to the last 10-day period of December 2010 were derived. The in-situ observations were used to validate the downscaled ECV_SM. In general, the downscaled soil moisture values for different land cover and land use types are consistent with the in-situ observations. Mean square root error is reduced from 0.070 to 0.061 by using 1970 in situ time series observation data from 28 sites distributed over different land uses and land cover types. The performance was also assessed using the $\mathrm{G}_{\mathrm{DOWN}}$ metric, a measure of the overall performance of the downscaling methods based on the same dataset. It was positive in $71.429 \%$, indicating that the suggested method in the paper generally improves the representation of soil moisture at 1-km resolution.
\end{abstract}

Keywords: Microwave remote sensing, essential climate variable (ECV) soil moisture, multi-source data, downscaling, accuracy verification, China

*Ru An, E-mail: anrunj@163.com

\section{Introduction}

Soil moisture conditions influence surface runoff and modulate interactions between the land surface and the atmosphere. ${ }^{1}$ Microwave remote sensing retrievals of soil moisture provide an alternative to in-situ observation networks, yielding spatially continuous information over a range of scales. Recently, various microwave remote sensing satellites have been launched to derive soil moisture information. Satellite-based soil moisture datasets are generated by scientists from several microwave sensors including the Scanning Multi-channel Microwave Radiometer (SMMR), Special Sensor Microwave Imagers (SSM/I), Microwave Imager (TMI), Advanced Microwave Scanning 
Radiometer-Earth Observing System (AMSR-E), European Remote Sensing Satellites (ERS), Active Microwave Instrument (AMI), Meteorological Operational Satellite (MetOp), and Advanced Scatterometer (ASCAT). ${ }^{2-6}$ These soil moisture datasets are derived from sensors that were not specifically designed to measure soil moisture. Therefore, the Soil Moisture and Ocean Salinity (SMOS) and the Soil Moisture Active Passive (SMAP) missions were launched by the European Space Agency (ESA) in 2009 and the National Aeronautics and Space Administration (NASA) in 2015, respectively. ${ }^{7-8}$ In addition to SMOS and SMAP, the successful launching of AMSR-2 and Sentinel-1A and 1-B guarantees the continuity of soil moisture products.

Individual microwave products do not often cover the period required for a climatological or hydrological analysis. Additionally, the difference in systems and mission designs and the use of different retrieval algorithms have led to data with varying spatial-temporal quality. ${ }^{9-10}$ Studies by Dorigo et al. (2010), Albergel et al. (2012), Njoku and Li (1999), and Taylor et al. (2012) indicated that active and passive microwave data are complementary for different land cover types. ${ }^{9,11-13}$ Also, radiometers generally perform best over dry areas while scatterometers perform best over densely vegetated areas. Therefore, combining active and passive microwave datasets will contribute substantially to offering improved estimates for surface soil moisture at various scales. Liu et al. (2011, 2012) merged active and passive microwave products into single multi-decadal Essential Climate Variable soil moisture (ECV_SM). ${ }^{14-15}$ Dorigo et al. (2012a) were the first to globally assess trends in ECV_SM for the period 1988-2010. ${ }^{16}$ The authors compared these trends with soil moisture trends from two model-based surface soil moisture, precipitation, and vegetation datasets. Since then, validation of ECV_SM has been conducted worldwide. ${ }^{17-20}$

Although ECV_SM provides an unprecedented wealth of information for understanding global hydrological and climatological patterns, its low spatial resolution of $0.25^{\circ}$ limits practical 
application. To address this spatial-resolution issue, some downscaling strategies have been proposed. $^{21-27}$ These include building a model for soil moisture using Normalized Difference Vegetation Index (NDVI), Land Surface Temperature (LST), Brightness Temperature (BT), and Surface Reflectance (SR) to obtain a high-spatial-resolution soil moisture dataset. ${ }^{21-23}$ Zhao and Li (2013) applied two temperature temporal variation parameters related to soil moisture, i.e., midmorning rising rate and daily maximum temperature time, to replace LST based on MSG-SEVIRI data. $^{28}$ Also, researchers have used a semi-empirical soil evaporative efficiency model to link microwave-derived soil moisture with red, near-infrared, and thermal-infrared data. ${ }^{24-25 ; 29-30}$ Kim and Hogue (2012) proposed a downscaling method (UCLA method) based on the Soil Wetness (SW) developed by Jiang and Islam. ${ }^{23,31}$ In this method, a simple ratio constructed between the MODISderived SW and the mean of the MODIS-based SW within each AMSR-E pixel was used to obtain the soil moisture at the MODIS spatial scale.

In this paper, we apply three different downscaling techniques to ECV_SM data collected over China, including linear, nonlinear, and hybrid modeling approaches, to identify a downscaling approach that is suitable for areas with large spatial heterogeneity and that is multi-temporal ${ }^{32-34}$. These test, use, and evaluate nine types of environmental parameters that affect soil moisture, which were derived from multiple auxiliary datasets. The downscaling results are evaluated using a large dataset of in-situ observations, collected over different land uses and land cover types. The performances of the downscaling methods are assessed by $G_{D O W N}$, which is a measure of the overall performance of the downscaling methods. The output is a ten-day spacing time series of $1 \mathrm{~km}$ resolution soil moisture maps spanning the years 2003-2010. This work provides a reference method and data for the application of ECV_SM in areas that need high-spatial-resolution soil moisture data. 


\section{Methods of Downscaling}

\subsection{Independent explanatory variables for soil moisture}

Studies have showed that the main factors affecting soil moisture are climate, terrain, and land surface and soil characteristics. The downscaling models tested here made use of nine explanatory variables, each of which is important in controlling soil moisture and can be described spatially over large areas with reasonable accuracy. Surface parameters evaluated include NDVI, LST, and BT; the meteorological parameters evaluated include the Antecedent Precipitation Index (API); the topographical parameters evaluated include altitude (ALT), slope, and aspect; and soil texture parameters evaluated include sand and clay.

Existing studies indicate there is a correlation among vegetation cover, surface temperature, and soil moisture. In some studies, the land surface temperature is used as a signature/proxy of soil moisture variability (via the evapotranspiration process or thermal inertia concept). ${ }^{22,24,35-37}$ The change in soil moisture leads to the change in the dielectric constant, and affects the reflectance of the soil surface. Thus, the brightness temperature recorded by a passive microwave remote sensing radiometer can be used to calculate soil moisture. ${ }^{4,38-39}$

The effects of meteorological factors on soil moisture are mainly by rainfall and temperature ${ }^{40-}$ 42. Rainfall characteristics are captured by the API and the temperature indicator is not included due to its strong correlation with LST. Proposed by Kohler and Linsley in the 1950s, API takes into account the cumulative effect of rainfall, and can represent soil water content. The API formula is as follows:

$$
A P I(i)=P(i)+k A P I(i-1)
$$

where API(i) denotes the first i days of the early precipitation index, $\mathrm{P}(\mathrm{i})$ denotes the precipitation of i days in $\mathrm{mm}, \mathrm{K}$ indicates the attenuation coefficient of the antecedent precipitation index, and the 
greater the $K$ value, the slower the attenuation. In this paper, the attenuation coefficient is $0.9 .{ }^{43}$ The expanded version of Equation (2) is as follows:

$$
A P I(i)=\sum_{d=0}^{\infty} k^{\mathrm{d}} \cdot P(i-d)
$$

This formula shows that the API is obtained by accumulating early day precipitation with weight $\left(K^{d}\right)$. Considering the attenuation characteristics of the antecedent precipitation, the precipitation effect of the first two months can be calculated.

The topographic factors that affect soil moisture are slope, aspect, and elevation. Soil water content has a decreasing trend with increasing slope gradient. The greater the slope, the lower the soil water content. The effect of slope direction on soil water content is the difference between it and the solar radiation. A south-facing slope receives more solar radiation energy that promotes soil temperature and enhances soil moisture evaporation thereby reducing soil moisture content. Permeability of soil moisture is influenced by altitude. That is, the permeability of soil moisture increases with an increase in altitude. In addition, low-altitude areas will be supplemented by surface runoff and subsurface runoff from high-altitude areas. ${ }^{44-48}$

Soil texture, structure and porosity affect the drainage and water storage capacity of the soil. Soil capillary conductivity, different soil textures, intergranular pores, soil particles and aggregates, and peripheral water film have varied characteristics, and thus, they affect soil moisture conditions accordingly. Studies have also shown that soil texture has different effects in different dry and wet areas. $^{44-46}$

The nine explanatory variables were calculated with data collected from January 2003 to December 2010. Changes in topographical and soil factors were likely small over the eight-year study period (2003-2010), so constant values were used. Other factors are dynamic parameters, which were acquired during the first, second, and third ten-days, respectively. The spatial resolution of the BT and the API is $25 \mathrm{~km}$, and the data were resampled to $1 \mathrm{~km}$. In order to eliminate 
dimensional disparities on the weight factor, a linear non-dimensional treatment was performed on the datasets and the results obtained ranged from 0-1.

\subsection{Downscaling models}

\subsubsection{Nonlinear model}

In climatic zones where surface types are uniform, NDVI, LST, and BT are closely related to soil moisture. The relationship between these elements can be quantitatively modeled as follows:

$$
S_{m}=\sum_{i=0}^{n} \sum_{j=0}^{n} \sum_{k=0}^{n} a_{i j k} N D V I^{i} L S T^{j} B T^{k}
$$

where $S_{m}$ represents the soil moisture. ${ }^{22}$

Related experimental studies have proven that a power index $(n)$ of 2 better expresses the soil moisture $S_{m}{ }^{49}$ An estimation model for soil moisture can be obtained from equation (3) by inputting $S_{m}, N D V I, L S T$, and $B T$ with a $25 \mathrm{~km}$ spatial resolution into the model and solving for the $a_{i j k}$ coefficient. A reduction in the soil moisture resolution from $25 \mathrm{~km}$ to $1 \mathrm{~km}$ can be realized by including the $1 \mathrm{~km}$ resolution parameters in the formula. Large-scale soil moisture has complex geographical variation that can affect the relationship between soil moisture and other factors, thereby limiting the performance of the global model.

\subsubsection{Linear model}

This method assumes a linear relationship between soil moisture and the influencing factors, as shown in equation (4).

$$
S_{m}=b_{1} N D V I+b_{2} L S T+b_{3} B T+b_{4} A P I+b_{5} S A N D+b_{6} C L A Y+b_{7} A L T+b_{8} S L O P E+b_{9} A S P E C T
$$

where $b_{i}$ is the coefficient.

A multiple-stepwise regression method can be used to solve the equation. In this approach, the independent variable is automatically selected based on the effect of each variable. This is done by 
eliminating the weak effects of the independent variables and retaining the significant independent variables. To test the overall fit of the linear model $\mathrm{F}$ tests were conducted.

\subsubsection{Hybrid models}

The nonlinear model better expresses the relationship between soil moisture and NDVI, LST, and $\mathrm{BT}^{[22]}$, but it does not contain a link to other factors. Therefore, fully considering the impact of NDVI, LST, and BT as well as the role of other factors, hybrid parameterization was adopted. Combining formulae (3) and (4) produces a hybrid model of the linear and nonlinear as follows:

$$
S_{m}=\sum_{i=0}^{n} \sum_{j=0}^{n} \sum_{k=0}^{n} a_{i j k} N D V I^{i} L S T^{j} B T^{k}+b_{1} A P I+b_{2} S A N D+b_{3} C L A Y+b_{4} A L T+b_{5} S L O P E+b_{6} A S P E C T
$$

\subsection{Downscaling implementation}

Downscaling can be achieved in two steps. In the first step, a regression model is established on a coarse-resolution scale with soil moisture and its corresponding multi-source auxiliary variables. In the second step, this regression model is applied to a fine-resolution scale for disaggregation. In this paper, the nine auxiliary variables (re-sampled to a $25 \mathrm{~km}$ scale as nine independent variables) along with CCI (as a dependent variable) in a $5 \times 5$ window are used to establish a regression model (backward mode) according to equations (3), (4), and (5), respectively. Then the soil moisture value at $1 \mathrm{~km}$ resolution is derived by bringing the auxiliary factors of $1 \mathrm{~km}$ resolution back into the established regression model pixel-by-pixel.

China is a vast territory with considerable variations in weather and surface conditions. These significant spatial variations influence studies on soil moisture so greatly that a global realization of a regression model is not ideal in this context. In view of this, the pixel to be estimated is taken as the center of a window. Each window is used as a single independent area. A moving window is established pixel-by-pixel. ${ }^{50}$ A high-resolution soil moisture dataset for China considering its spatial heterogeneity is derived using this method. A $5 \times 5$ square window can be selected for our experiment (refer to section 4.1) and following the work in [51]. The corresponding field area is 125 
$\times 125 \mathrm{~km}^{2}$. The influence of the size of the window on the performance of the modeling is shown in Table 2 . The best method was found to be a hybrid approach using a $5 \times 5$ window.

\subsection{Validation of downscaled results}

Agrometeorological station soil moisture data were used to validate the result of the downscaled soil moisture. Statistical indicators used for the testing include the correlation coefficient (R), mean deviation (B), absolute error (ABE), relative error (RE), root mean square error (RMSD), and $\mathrm{G}_{\mathrm{DOwN}}{ }^{52-53}$ The performance of the three models was assessed from the number of pixels which could establish an effective model and error valuation. The performance of the downscaled soil moisture data was also evaluated for various land cover and land use types. Finally, the accuracy of the ECV_SM and the corresponding downscaled results were compared and analyzed based on several typical site-specific datasets.

Olivier Merlin et al. (2015) proposed a new metric $\mathrm{G}_{\mathrm{DOWN}}$ to assess the overall performance of downscaling methods. ${ }^{53}$ It is a relevant, relatively complete, and robust performance metric to evaluate soil moisture downscaling methods using in-situ measurement time series. A positive $\mathrm{G}_{\text {DOWN }}$ indicates effective disaggregation and a negative value indicates the opposite case. The definitions and calculation formulas are as follows:

$$
\begin{gathered}
G_{D O W N}=\left(G_{E F F I}+G_{P R E C}+G_{A C C U}\right) / 3 \\
G_{E F F I}=\frac{\left|1-S_{L R}\right|-\left|1-S_{H R}\right|}{\left|1-S_{L R}\right|+\left|1-S_{H R}\right|} \\
G_{P R E C}=\frac{\left|1-R_{L R}\right|-\left|1-R_{H R}\right|}{\left|1-R_{L R}\right|+\left|1-R_{H R}\right|} \\
G_{A C C U}=\frac{\left|B_{L R}\right|-\left|B_{H R}\right|}{\left|B_{L R}\right|+\left|B_{H R}\right|}
\end{gathered}
$$




$$
\begin{gathered}
S_{X R}=R_{X R} \times \frac{\sigma_{X R}}{\sigma_{I S}} \\
R_{X R}=\frac{E\left[\left(S M_{X R}-E\left[S M_{X R}\right]\right)\left(S M_{I S}-E\left[S M_{I S}\right]\right)\right]}{\sigma_{X R} \sigma_{I S}} \\
B_{X R}=E\left[S M_{X R}\right]-E\left[S M_{I S}\right] \\
G_{R M S D}=\frac{R M S D_{L R}-R M S D_{H R}}{R M S D_{L R}+R M S D_{H R}}
\end{gathered}
$$

where $G_{D O W N}$ is a performance metric dedicated to downscaling methods; $G_{E F F I}$ is the disaggregation (efficiency) gain on the bias in the slope of the linear fit relative to the non-disaggregation case; $G_{E F F I}$ can be interpreted as characterizing the efficiency of the disaggregation method; $G_{P R E C}$ is the disaggregation (precision) gain on a time series correlation relative to the non-disaggregation case; $G_{P R E C}$ can be interpreted as characterizing the precision of the disaggregation method to be evaluated; $G_{A C C U}$ is the disaggregation (accuracy) gain on the mean bias relative to the nondisaggregation case; $G_{A C C U}$ can be interpreted as characterizing the accuracy of the disaggregation method; $\sigma_{X R}$ is the standard deviation of satellite soil moisture; and ${ }^{\sigma_{I S}}$ is the standard deviation of in-situ soil moisture. $S$ is slope of the linear regression between satellite estimation and the fine-scale true soil moisture measurement, and $G_{R M S D}$ is the disaggregation $(R M S D)$ gain on the root mean square difference relative to the non-disaggregation case. $H R$ refers to high resolution, $L R$ refers to low resolution, and $X R$ denotes either high or low resolution. $I S$ refers to in-situ soil moisture.

One key advantage of $G_{D O W N}$ over other performance metrics is it provides an estimate of the overall improvement in soil moisture data with a single value. $G_{D O W N}$ provides a single quality assessment of disaggregated data while being based on three relevant and complementary performance metrics: $S, R$, and $B$. The advantage of $G_{D O W N}$ over the $R M S D$ is two-fold: (1) $G_{D O W N}$ is computed relative to the non-disaggregation case, so it is better suited to relative comparisons; and (2) 
the relative nature of $G_{D O W N}$ makes it a priori much less sensitive than the RMSD to any bias in the mean or in the variance. Moreover, the normalization of $S_{H R}, R_{H R}$, and $B_{H R}$ (by $S_{L R}, R_{L R}$, and $\left.B_{L R}\right)$ can significantly reduce the impact on the performance metrics of uncertainties in LR data and the lack of representativeness of localized in-situ measurements at the downscaling resolution. Olivier Merlin et al. (2015) believe that $G_{D O W N}$ is a relevant, relatively complete, and robust performance metric to evaluate soil moisture downscaling methods using in-situ measurement time series. For more detailed information refer to reference [53].

\section{Study Area and Dataset}

\subsection{Study Area}

China is a vast nation of approximately 9.6 million $\mathrm{km}^{2}$. It is located between $3^{\circ} 51^{\prime} \mathrm{N}-53^{\circ} 33^{\prime} \mathrm{N}$ and $73^{\circ} 33^{\prime} \mathrm{E}-135^{\circ} 05^{\prime} \mathrm{E}$ in eastern Asia, and borders the western edge of the Pacific Ocean (Figure 1). It has three obvious elevational areas, from high elevations in the west to low elevations in the east. The overall terrain is characterized by five basic terrain types, namely plateau, plain, basin, ridge, and hill. Mountainous areas account for two thirds of the total surface area. The large expanse of China across a wide latitudinal range coupled with these various terrain types leads to diverse and variable temperature and precipitation conditions.

China's climate is significantly influenced by both continental and oceanic conditions due to its geographic location. It has typical characteristics of a monsoon climate. The climate is characterized by high temperatures and rain in summer and cold temperatures in winter. Large temperature differences occur between winter and summer. The annual precipitation decreases from the southeastern coastal regions to the northwestern inland regions. Climate zones is include coldtemperate, mild-temperate, warm-temperate, subtropical, and tropical. ${ }^{18}$ 


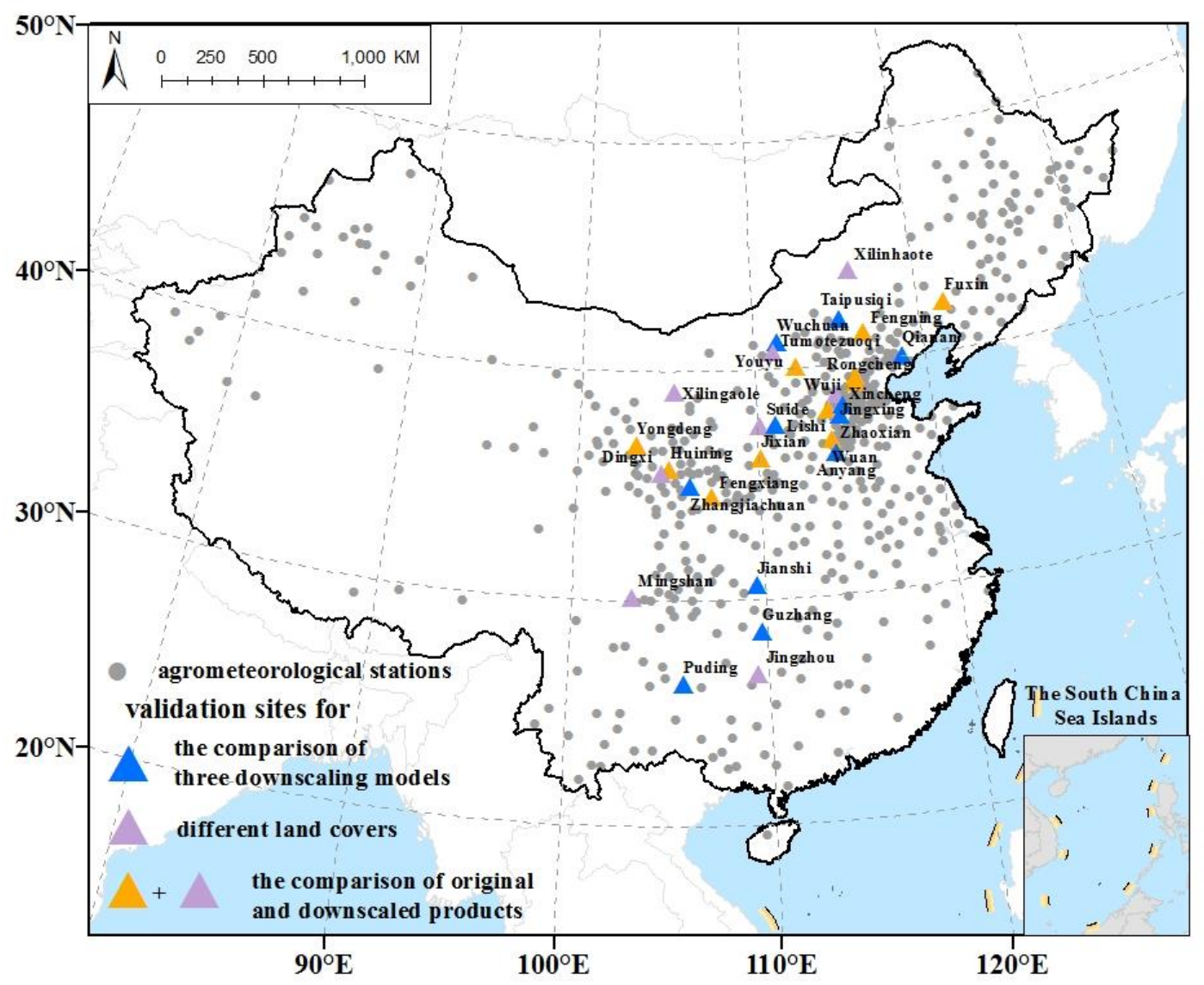

Fig. 1 Study area and locations of the ground-based validation sites used in this study.

\subsection{ECV_SM}

ECV_SM (Version 2.0) is a newly merged soil moisture product developed under the framework of the European Space Agency's Water Cycle Multi-Mission Observation Strategy (WACMOS) and the Soil Moisture Climate Change Initiative (CCI) projects. The product is generated by space-borne active and passive microwave instruments, and originates from a number of Earth Observation (EO) missions, agencies, and sensor systems. The active dataset is generated by the University of Vienna using observations from the C-band scatterometers on board ERS-1/2 and METOP-A. The passive dataset is generated by the VU University Amsterdam in collaboration with NASA using passive microwave observations from Nimbus 7 SMMR, DMSP SSM/I, TRMM TMI, Aqua AMSR-E, 
Coriolis WindSat, and GCOM-W1 AMSR2. As shown in Figure 2, the suite of datasets covers a 35year period from the late 1970s to the present. The datasets are expected to be continuous into the next decade. At present, the product provides global coverage at a spatial resolution of 0.25 degrees. ${ }^{14,19-20,54}$ This product was obtained from the ESA website (http://www.esa-soilmoisturecci.org/).

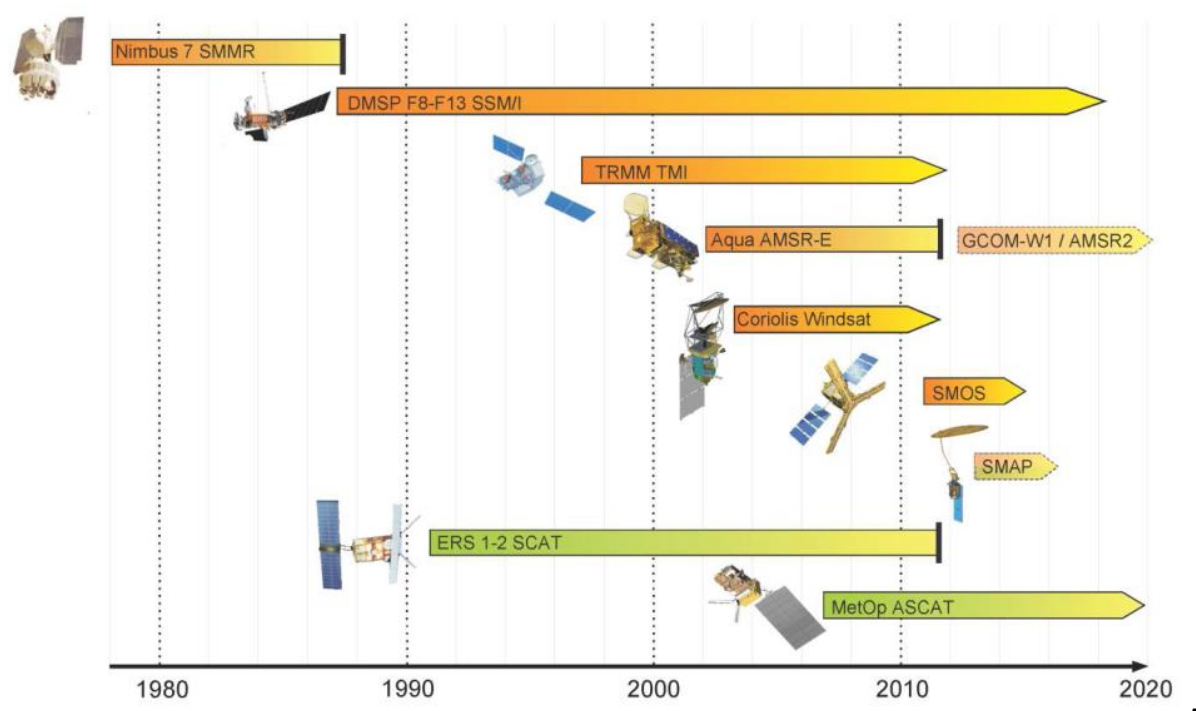

Fig. 2 An overview of the active and passive sensors that provide the ECV_SM product. ${ }^{\mathbf{5 4}}$

The maximum merging method was used to process ECV_SM and to unify the time periods of ECV_SM and the in-situ datasets. This was because observations of the soil moisture data from the agrometeorological stations were collected on the eighth day of every ten-day interval of each month. ${ }^{55}$ The ECV_SM data observed on the $7^{\text {th }}, 8^{\text {th }}$, and $9^{\text {th }}$ day of every month were merged. A similar procedure was performed on the $17^{\text {th }}, 18^{\text {th }}$, and $19^{\text {th }}$ days and on the $27^{\text {th }}, 28^{\text {th }}$, and $29^{\text {th }}$ days. This procedure retains the temporal characteristics of the soil moisture data and eliminates noise in these observations. Pixel values in ice-covered and densely vegetated regions that were not viable within the microwave band were rejected. A $5 \times 5$ moving window was used to inspect every pixel and fill the rejected pixels by averaging nearby values. ${ }^{55}$ 


\subsection{Ground-based data}

The agrometeorological soil moisture data derived from the Chinese crop growth and farmland soil moisture dataset were downloaded from the China Meteorological Data Sharing Service System (http://cdc.cma.gov.cn/home.do) for the 2007-2010 periods. The data were collected on the $8^{\text {th }}, 18^{\text {th }}$, and $28^{\text {th }}$ days of every month at depths of $10,20,30,50,70$, and $100 \mathrm{~cm}$. Based on the sampling depth of ECV_SM, the data within the upper $10 \mathrm{~cm}$ of the soil profile were used. To be in accordance with ECV_SM datasets, the units of the in-situ dataset were converted from fraction of saturation $(\%)$ to volumetric water content $\left(\mathrm{m}^{3} \mathrm{~m}^{-3}\right)$ as used by An et al. (2016). ${ }^{18}$ The conversion rule is as follows:

$$
\theta_{v}=\theta_{r} \cdot \text { por }
$$

where $\theta_{v}$ is the volumetric water content $\left(\mathrm{m}^{3} \mathrm{~m}^{-3}\right) ;{ }_{r}$ is the fraction of saturation $(\%)$; and por is a map of the porosity (\%), which provides ancillary data along with ECV_SM.

Fig. 1 shows the locations of the ground-based validation sites used in this study, including 533 agrometeorological stations. For verification of downscaled soil moisture for forests, grasslands, croplands, and urban/developed lands, 26639 observations from 2007 to 2010 at these stations were used in computing the statistical measures. Taking into account the computational effort, sites of different land use types, of large spatial distance, and where CCI and in-situ data are nearly complete were randomly selected for analysis. Of these sites, eleven were used in the comparison of the three downscaling models (blue triangles). Twenty-eight stations (identified by purple and yellow triangles) were used in analyzing the performance of the modeling, auxiliary variables, and window size and in inter-comparison between the original and downscaled versions. 


\subsection{Auxiliary datasets}

The NDVI and LST datasets over China were downloaded from the Geospatial Data Cloud (http://www.gscloud.cn/). These are derived from daily MODIS data. The NDVI dataset and LST dataset were comprised of the maximums of ten-day values and the average of ten-day values, respectively. These were gridded using the WGS- 84 projection and provide national coverage of China at a spatial resolution of $1 \mathrm{~km}$. It was found that the LST has a small number of missing data.

The BT dataset from the AMSR-E Level-3 land surface product (AE_Land 3) was downloaded from the American National Snow and Ice Data Center (http://www.nsidc.org). The data with a 56 $\mathrm{km}$ mean spatial resolution were resampled to a global cylindrical $25 \mathrm{~km}$ Equal-Area Scalable Earth Grid (EASE-Grid) cell spacing. The data were stored in an HDF-EOS format and were available via FTP from June $19^{\text {th }}, 2002$ to October $3^{\text {rd }}, 2011$.

The daily gridded precipitation data were extracted from real-time rainfall data from over 2400 sites and were downloaded from the China Meteorological Data Sharing Service System (http://cdc.cma.gov.cn/home.do).

Topographical data used in this paper were downloaded from the Cold and Arid Regions Science Data Center (http://westdc.westgis.ac.cn). Digital elevation model (DEM), slope, and aspect datasets were used. The spatial resolution was $1 \mathrm{~km}$ and the file format was a geotiff.

The soil dataset of China, which is from the Harmonized World Soil Database (HWSD), was downloaded from the Heihe Plan Science Data Center of the National Natural Science Foundation of China (www.heihedata.org). The dataset includes soil name, classification, texture, depth, and water content as well as sand and silt content. The data were gridded using the WGS-84 projection.

The land use and land cover products for China were downloaded from the Cold and Arid Regions Science Data Center (http://westdc.westgis.ac.cn). In these products, China's land surface is 
divided into 17 categories, mainly including evergreen broadleaf forests, grasslands, permanent wetlands, croplands, urban and developed lands, glaciers and water bodies, etc. ${ }^{56-57}$

\section{Results and Discussion}

\subsection{Evaluation of model type, auxiliary variables, and window size}

Taking the second ten days of August 2010 as an example to analyze the performance of the modeling, auxiliary variables, and window size, 28 sites are distributed around the area and were randomly selected for modeling (Figure 1). These sites are located in different biological climate zones, and are located far apart from each other. We can see that the dominant factor at some sites is API, such as at Huining, where $\mathrm{SM}=0.117+0.691 \times \mathrm{API}, \mathrm{R}$ is 0.750 , and Sig is 0.000 . At some other sites, it is LST, such as at Wuan, where SM=0.783-0.598×LST, R is 0.638, and Sig is 0.001. Some sites have several dominant influencing factors working together, such as at Xilinhaote, where $\mathrm{SM}=0.48-0.509 \times \mathrm{BT}+0.477 \times \mathrm{NDVI}+0.27 \times \mathrm{CLAY}, \mathrm{R}$ is 0.835 , and $\mathrm{Sig}$ is 0.000 (all these results are based on the linear model and a $5 \times 5$ window). It can be seen from these models that they have different dominant influencing factors and weights. These models can reflect the spatial heterogeneity of soil moisture and their dominant influencing factors. There are 25 sites with established significant regression models ( $\mathrm{Sig}$ is less than 0.05 ). The mean $\mathrm{R}$ is 0.67 for 28 sites. It is shown that the established models and auxiliary variables that were selected are effective in evaluating soil moisture. The frequency and average weight of the auxiliary variables used in the modeling is shown in Table 1 (the linear model and $5 \times 5$ window were used).

Table 1 Frequency and weight of auxiliary variables used in the modeling

\begin{tabular}{|cccccccccc|}
\hline $\begin{array}{c}\text { Auxiliary } \\
\text { variables }\end{array}$ & API & $B T$ & LST & NDVI & ASPECT & ALT & SLOPE & SAND & CLAY \\
\hline Frequency & 9 & 10 & 4 & 9 & 6 & 9 & 6 & 4 & 7 \\
$\begin{array}{c}\text { Average } \\
\text { weight }\end{array}$ & 0.59 & 0.57 & 0.52 & 0.47 & 0.32 & 0.43 & 0.31 & 0.43 & 0.48 \\
\hline
\end{tabular}


We can see that other than $L S T$ and $S A N D$, the frequency of the factors involved in the modeling is high. The average weight of each factor is different. The higher values are for $A P I, B T$, $L S T, C L A Y, N D V I, A L T$, and SAND in this case. The auxiliary variables with higher frequency and weight are $A P I, B T, N D V I, A L T$, and CLAY.

The modeling performance of different size windows is shown in Table 2. We can see that the correlation of the Hybrid model decreased with an increase in window size. The performance of the Hybrid model is the best among three types of models in each window. Finally, we found that the best-performing model is the Hybrid model in a $5 \times 5$ window.

Table 2 Modeling performance for different size windows

\begin{tabular}{|c|c|c|c|c|c|c|c|c|c|}
\hline \multirow{2}{*}{$\begin{array}{l}\text { Window size } \\
\text { Model }\end{array}$} & \multicolumn{3}{|c|}{$5 \times 5$} & \multicolumn{3}{|c|}{$7 \times 7$} & \multicolumn{3}{|c|}{$9 \times 9$} \\
\hline & linear & Nonlinear & Hybrid & linear & Nonlinear & Hybrid & linear & Nonlinear & Hybrid \\
\hline Mean R & 0.67 & 0.65 & 0.79 & 0.65 & 0.47 & 0.73 & 0.67 & 0.53 & 0.71 \\
\hline $\begin{array}{l}\text { Number of effective } \\
\text { model }(\text { Sig } \leqslant 0.05)\end{array}$ & 25 & 25 & 27 & 26 & 26 & 27 & 26 & 26 & 27 \\
\hline
\end{tabular}

\subsection{Downscaling effect of the three models}

A total of 36 soil moisture maps in 2010 were selected in comparing the modeling effects of the three models. The results show that the combined nonlinear and linear model has more pixels which can establish a more effective model $(\mathrm{Sig} \leqslant 0.05)$ than that of other two models. Because frozen soil and high vegetation coverage were removed during the fusion process, ${ }^{58}$ the soil moisture time series data in most areas were not complete. The null pixel values of ECV_SM occurred more often in January, February, March, November, and December for the year. Thus, large areas could not be modeled during these times. Accounting for the total number of pixels (except for the number of ECV_SM null value pixels), about $95 \%$ of the pixels can be modeled successfully. The numbers of pixels effectively modeled are 201,479, 215,985, and 226,648 using the nonlinear, linear, and hybrid models, respectively. 
In addition, to further compare the accuracy of the three models and validate the downscaled ECV_SM soil moisture data, several in-situ observation soil moisture data points were selected randomly by considering land cover and land use type and spatial distribution. The distribution of these sites is shown in Figure 1. The absolute errors using the nonlinear, linear, and combined models are $0.048,0.046$, and $0.048 \mathrm{~m}^{3} \mathrm{~m}^{-3}$, respectively. The RMSD is $0.060,0.060$, and $0.063 \mathrm{~m}^{3} \mathrm{~m}^{-3}$, respectively. The accuracy $((1-\mathrm{RE}) \times 100 \%)$ of the three modeling methods is $71.137 \%, 73.145 \%$, and $72.218 \%$, respectively. It can be seen that the statistical errors of all three models are small. Among them, the linear model is slightly better than other two models. Considering the performance of the modeling (section 4.1), the number of established effective models, and the error performance, the hybrid model with a $5 \times 5$ window was selected as the final downscaling method. Figure 3 shows the soil moisture maps of ECV_SM and the downscaled results during the first ten days of October in 2010. The general trend of the spatial distribution of soil moisture is consistent, and the spatial detail of soil moisture was significantly enhanced after downscaling.

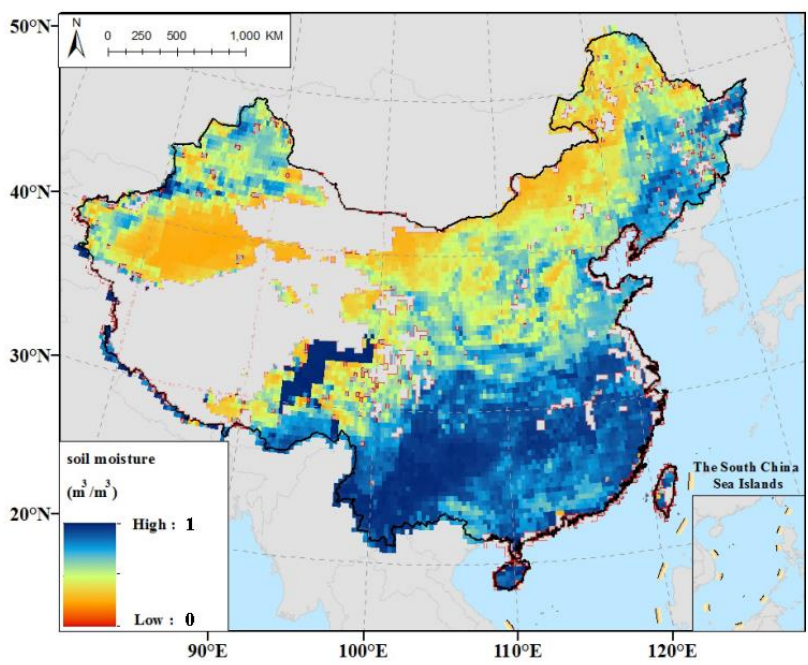

(a)

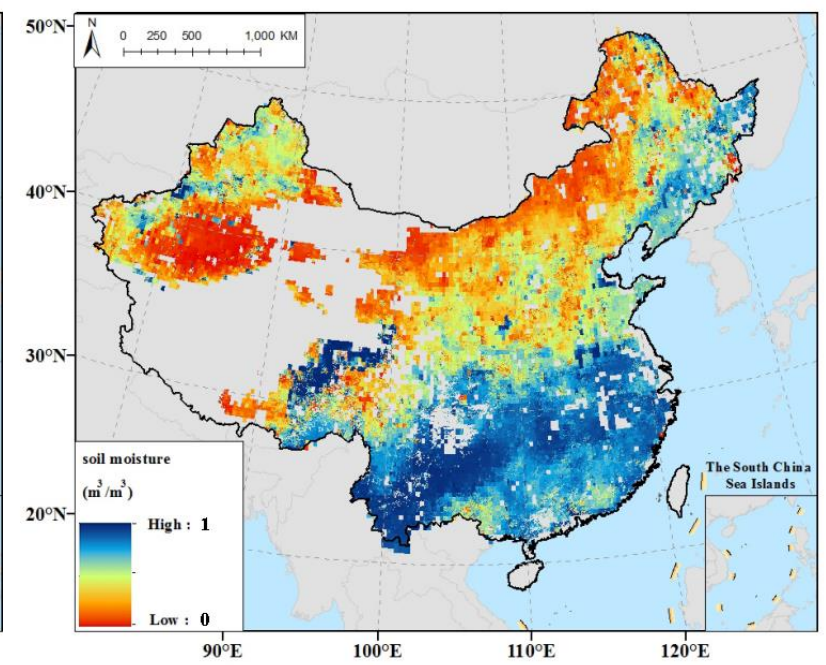

(b)

Fig. 3 Distribution of soil moisture of ECV_SM and downscaled during the first ten days of October in 2010: (a) original ECV_SM; (b) ECV_SM downscaled. 


\subsection{Comparison between the downscaled and original ECV_SM}

In order to further verify the reliability and accuracy of the downscaled ECV_SM data, in-situ observation soil moisture data was used. Twenty-eight sites with more complete time series data were used (Table 3). The spatial distribution of these selected stations is shown in Figure 1. As seen in Table 3, it was found that within our data ensemble, GDown is positive in $71.429 \%$ of the cases, indicating that the methods suggested in this paper generally improve the representation of soil moisture at $1 \mathrm{~km}$ resolution. The disaggregation gain in precision (GPREC) and efficiency (GEFFI) is positive in $67.875 \% \%$ and $71.429 \%$ of the cases, respectively. The disaggregation gain in accuracy ( $\mathrm{GACCU}$ ) is positive in $71.429 \%$ and the GRMSD is positive in $85.714 \%$ of the cases.

Verification of soil moisture for forests, grasslands, croplands, and urban/developed lands was also carried out. A total of 26,639 observations from 2007 to 2010 from 533 sites were used in computing the statistical measures. The overall accuracy for grassland and farmland was relatively high with an average relative error of 0.362 and 0.313 , respectively. Also, the root mean square errors were 0.087 and 0.091 , respectively. Figure 4 shows the correlation between in-situ values of soil moisture and the downscaled values at four sites with four land use and land cover types. It can be seen that the downscaled soil moisture for the different land cover and land use types is consistent with the in-situ observations. RMSD are improved after downscaling. Here, RMSD $\mathrm{HR}_{\text {is calculated }}$ from downscaled result and in-situ data. $\mathrm{RMSD}_{\mathrm{LR}}$ is calculated from CCI and in-situ data.

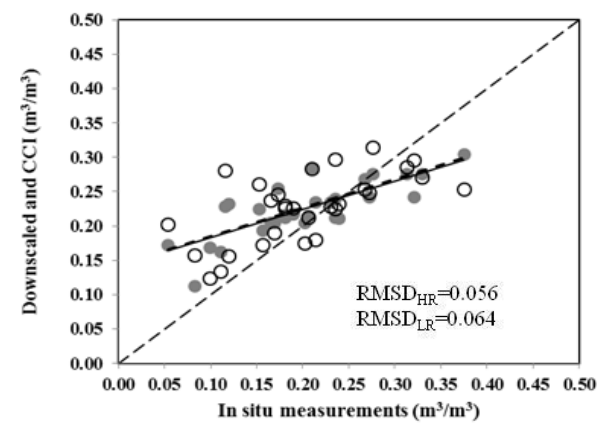

(a)

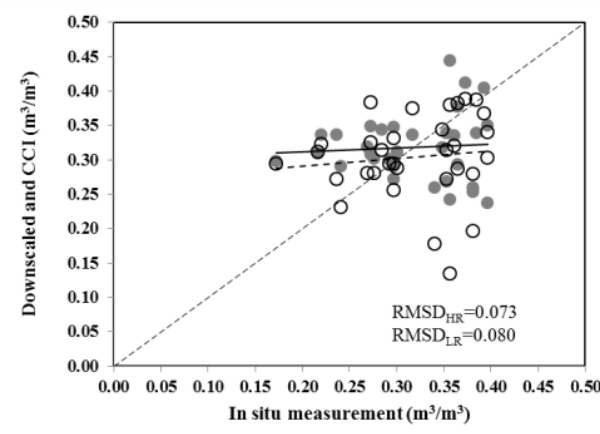

(c)

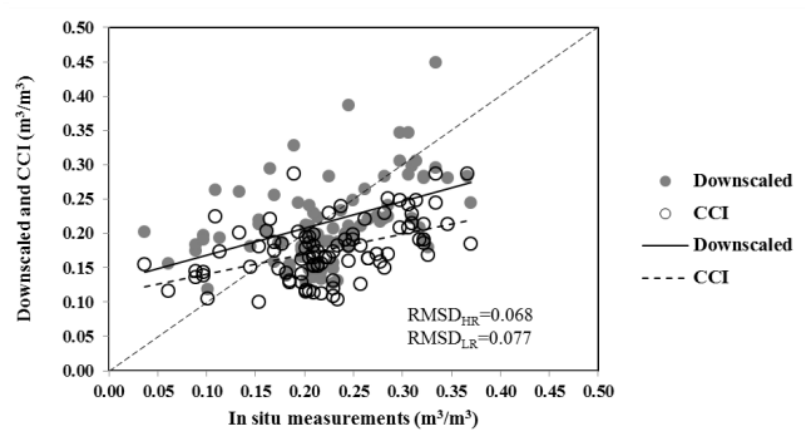

(b)

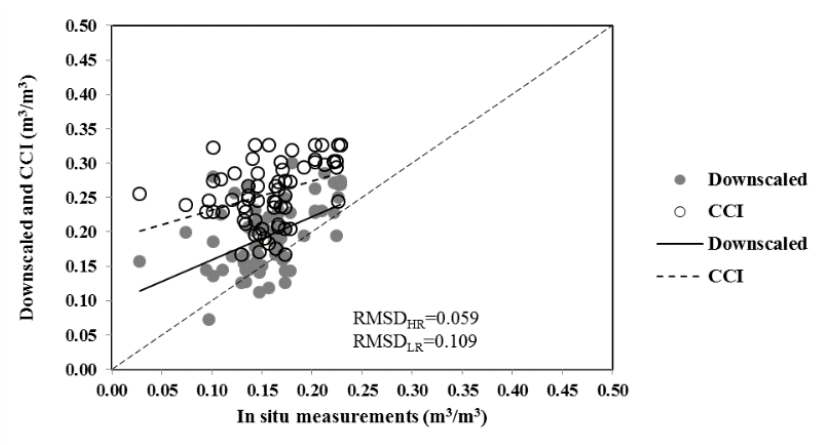

(d)

Fig. 4 Correlation between the in situ values of soil moisture and the down-scaled one in four land use and land cover types at: (a) Dingxi (Grasslands, 29 data pairs) ; (b) Fuxing（urban and built-up lands, 91 data pairs) ; (c) Jingzhou (Forests, 32 data pairs) ; (d)Youyu (Farmland, 66 data pairs) 
Table 3 Statistical results for each site

\begin{tabular}{|c|c|c|c|c|c|c|c|c|c|c|c|c|c|c|c|}
\hline Site & $\begin{array}{l}\text { Sample } \\
\text { Counts }\end{array}$ & $\begin{array}{l}\text { LULC } \\
\text { Type }\end{array}$ & $\mathrm{R}_{\mathrm{HR}}$ & $\mathrm{S}_{\mathrm{HR}}$ & $\begin{array}{c}\mathrm{B}_{\mathrm{HR}} \\
\mathrm{m}^{3} \mathrm{~m}^{-3}\end{array}$ & $\begin{array}{c}\mathrm{RMSD}_{\mathrm{HR}} \\
\mathrm{m}^{3} \mathrm{~m}^{-3}\end{array}$ & $\mathrm{R}_{\mathrm{LR}}$ & $\mathrm{S}_{\mathrm{LR}}$ & $\begin{array}{c}\mathrm{B}_{\mathrm{LR}} \\
\mathrm{m}^{3} \mathrm{~m}^{-3}\end{array}$ & $\begin{array}{c}\mathrm{RMSD}_{\mathrm{LR}} \\
\mathrm{m}^{3} \mathrm{~m}^{-3}\end{array}$ & $\mathrm{G}_{\mathrm{RMSD}}$ & $\mathrm{G}_{\mathrm{EFFI}}$ & $\mathrm{G}_{\text {PREC }}$ & $\mathrm{G}_{\mathrm{ACCU}}$ & $\mathrm{G}_{\text {DOWN }}$ \\
\hline Guzhang & 27 & Forest & 0.141 & -0.082 & -0.016 & 0.069 & 0.100 & -0.080 & -0.008 & 0.075 & 0.038 & -0.001 & 0.023 & -0.333 & -0.104 \\
\hline Jingzhou & 32 & Forest & 0.063 & 0.055 & 0.001 & 0.073 & 0.105 & 0.110 & -0.013 & 0.080 & 0.046 & -0.030 & -0.023 & 0.816 & 0.255 \\
\hline Fengxiang & 104 & Grassland & 0.550 & 0.608 & 0.067 & 0.088 & 0.535 & 0.427 & 0.076 & 0.091 & 0.017 & 0.188 & 0.016 & 0.063 & 0.089 \\
\hline Huining & 82 & Grassland & 0.443 & 0.267 & 0.038 & 0.082 & 0.438 & 0.207 & 0.041 & 0.083 & 0.006 & 0.039 & 0.004 & 0.038 & 0.027 \\
\hline jixian & 91 & Grassland & 0.455 & 0.598 & -0.044 & 0.066 & 0.382 & 0.576 & -0.043 & 0.073 & 0.050 & 0.027 & 0.063 & -0.011 & 0.026 \\
\hline Dingxi & 29 & Grassland & 0.789 & 0.414 & 0.023 & 0.056 & 0.638 & 0.413 & 0.025 & 0.064 & 0.067 & 0.001 & 0.264 & 0.042 & 0.102 \\
\hline Mingshan & 45 & Grassland & 0.197 & 0.377 & -0.012 & 0.058 & 0.190 & 0.317 & -0.088 & 0.102 & 0.274 & 0.046 & 0.004 & 0.764 & 0.272 \\
\hline Suide & 55 & Grassland & 0.721 & 0.573 & 0.004 & 0.068 & 0.655 & 0.396 & -0.011 & 0.074 & 0.047 & 0.172 & 0.106 & 0.493 & 0.257 \\
\hline Hezhang & 84 & Grassland & 0.204 & 0.168 & -0.022 & 0.062 & 0.187 & 0.154 & -0.017 & 0.061 & -0.008 & 0.008 & 0.009 & -0.128 & -0.037 \\
\hline Wuan & 103 & Farmland & 0.327 & 0.499 & -0.012 & 0.058 & 0.430 & 0.631 & -0.030 & 0.059 & 0.009 & -0.152 & -0.083 & 0.429 & 0.065 \\
\hline Fengning & 73 & Farmland & 0.509 & 0.876 & -0.021 & 0.052 & 0.539 & 0.841 & -0.039 & 0.058 & 0.055 & 0.124 & -0.032 & 0.300 & 0.131 \\
\hline Youyu & 66 & Farmland & 0.506 & 0.626 & -0.037 & 0.059 & 0.372 & 0.421 & -0.098 & 0.109 & 0.298 & 0.215 & 0.119 & 0.452 & 0.262 \\
\hline Yongdeng & 74 & Farmland & 0.484 & 0.340 & -0.010 & 0.062 & 0.523 & 0.366 & -0.074 & 0.095 & 0.210 & -0.020 & -0.039 & 0.762 & 0.234 \\
\hline Wuji & 79 & Farmland & 0.203 & 0.537 & -0.018 & 0.056 & 0.156 & 0.398 & -0.023 & 0.057 & 0.009 & 0.131 & 0.029 & 0.122 & 0.094 \\
\hline Lintao & 83 & Farmland & 0.658 & 0.427 & 0.007 & 0.054 & 0.575 & 0.371 & 0.007 & 0.059 & 0.044 & 0.046 & 0.108 & 0.000 & 0.052 \\
\hline Cahaeryouyi & 80 & Farmland & 0.298 & 0.197 & 0.005 & 0.061 & 0.244 & 0.149 & -0.011 & 0.062 & 0.008 & 0.029 & 0.037 & 0.375 & 0.147 \\
\hline Lishi & 60 & Farmland & 0.677 & 0.659 & 0.000 & 0.044 & 0.420 & 0.413 & 0.007 & 0.060 & 0.152 & 0.265 & 0.285 & 0.927 & 0.492 \\
\hline Tumotezoqi & 46 & Farmland & 0.507 & 0.347 & -0.010 & 0.053 & 0.522 & 0.613 & -0.004 & 0.064 & 0.091 & -0.256 & -0.015 & -0.412 & -0.228 \\
\hline Quyang & 74 & Farmland & 0.416 & 0.369 & -0.009 & 0.033 & 0.479 & 0.935 & 0.020 & 0.057 & 0.268 & -0.813 & -0.057 & 0.405 & -0.155 \\
\hline Zhaoxian & 88 & Farmland & 0.221 & 0.493 & 0.025 & 0.050 & 0.235 & 0.685 & 0.033 & 0.064 & 0.127 & -0.234 & -0.008 & 0.139 & -0.034 \\
\hline Jingxing & 92 & Urban & 0.157 & 0.232 & 0.033 & 0.068 & 0.211 & 0.290 & 0.047 & 0.072 & 0.029 & -0.040 & -0.033 & 0.175 & 0.034 \\
\hline Fuxin & 91 & Urban & 0.456 & 0.394 & 0.007 & 0.068 & 0.478 & 0.294 & 0.047 & 0.077 & 0.062 & 0.076 & -0.021 & 0.741 & 0.265 \\
\hline Rongcheng & 102 & Urban & 0.301 & 0.875 & -0.017 & 0.057 & 0.253 & 0.670 & 0.021 & 0.055 & -0.018 & 0.451 & 0.033 & 0.105 & 0.196 \\
\hline Xincheng & 64 & Urban & 0.584 & 0.897 & -0.030 & 0.053 & 0.539 & 0.835 & -0.039 & 0.061 & 0.070 & 0.230 & 0.051 & 0.130 & 0.137 \\
\hline Puding & 79 & Urban & 0.709 & 0.672 & -0.041 & 0.054 & 0.583 & 0.626 & -0.017 & 0.047 & -0.065 & 0.066 & 0.178 & -0.424 & -0.060 \\
\hline Taipusiqi & 66 & Urban & 0.388 & 0.294 & -0.026 & 0.055 & 0.250 & 0.241 & -0.004 & 0.058 & 0.029 & 0.036 & 0.101 & -0.765 & -0.209 \\
\hline Wuchuan & 22 & Urban & 0.627 & 0.473 & 0.053 & 0.072 & 0.427 & 0.264 & -0.012 & 0.058 & -0.107 & 0.165 & 0.211 & -0.644 & -0.089 \\
\hline Xilinguole & 79 & Bare land & 0.544 & 0.199 & 0.021 & 0.081 & 0.322 & 0.159 & 0.019 & 0.090 & 0.050 & 0.024 & 0.196 & -0.067 & 0.051 \\
\hline
\end{tabular}


5 A downscaled method of evaluating soil moisture that was suitable for China on a national scale was established based on a linear and nonlinear hybrid model combined with a moving window, ECV_SM product, and auxiliary datasets. Comparing the downscaled results of the linear, nonlinear and hybrid model, it was found that the three models had varying but good 9 performance. From analyses of several typical sites, it was found that the established and 10 auxiliary variables selected for the models were effective. The frequency of the factors involved 11 in the modeling were all high except for LST and SAND. The average weight of each factor is 12 different. The auxiliary variables with a higher frequency and greater weight are API, BT, NDVI, 13 ALT, and CLAY in this case. By analyzing the performance of each model in three different size 14 windows, it was found that the Hybrid model in $5 \times 5$ window is the best in this case, and it was selected as the final downscaling model. The method described here is a simple and practical soil moisture downscaling method which is suitable for large-scale and multi-temporal assessments. The down-scaled ECV_SM product was validated from different land cover and land use types by using in-situ observations of soil moisture and classic error statistical indicators as well as a novel $\mathrm{G}_{\mathrm{DOWN}}$ metric. The overall accuracy for grassland and farmland are relatively high. Mean square root error is reduced from 0.070 to 0.061 after downscaling. $G_{\text {DOWN }}$ is positive $71.429 \%$ of the time using in-situ observation data, indicating that the method suggested in the paper is effective in this case. A total of 288 soil moisture maps of $1 \mathrm{~km}$ resolution from the first ten-day period of January 2003 to the last ten-day period of December 2010 were derived by using the downscaling method. It can provide a reliable data set for research and application in many 
related fields and for further analysis of space and time characteristics of China's regional soil moisture.

More research will be needed on the interaction mechanism between soil moisture and auxiliary variables, parameter selection, and downscaling method improvements to increase the accuracy of downscaled soil moisture data even further. It is necessary to study the spatial and temporal variation characteristics of soil moisture in China in order to establish an adaptive window and improve downscaling performance. The ECV_SM null value is serious, and study of a method to complement and improve it is necessary. Collecting more validation data and increasing the reliability of the verification results are also needed in the future. Due to the missing CCI and LST data, it is necessary to more carefully complete calculation details in the future, which may further improve downscaling performance. Residual analysis will be introduced to ensure that the disaggregated SM reaggregates to the coarse-scale original map and to reduce error. ${ }^{59}$

\section{Acknowledgements}

The authors would like to express sincere thanks to the following researchers: Ji-Yuan Liu, Quan-Qin Shao, Jiang-Wen Fan of Institute of Geography Sciences and Natural Resources Research (CAS) for their immense suggestions, provision of research data and other assistance. This work is supported by the Key Projects in the National Science \& Technology Pillar Program during the Twelfth Five-Year Plan Period (No. 2013BAC03B04); the National Nature Science Foundation of China (No. 41271361;41271420); The ninth batch of qualified personnel project of "Six talent peaks" in Jiangsu province (No. XXRJ-011) and National Basic Research Program of China (No.2009CB421105). 
[1] M. F. McCabe, H. Gao, and E. F. Wood, "Evaluation of AMSR-E-derived soil moisture retrievals using ground-based and PSR airborne data during SMEX02," J.Hydrometeorology. 6, 864-877 (2005).

[2] M. Owe, R.A.M. de Jeu, and T. Holmes, "Multisensor historical climatology of satellite-derived global land surface moisture," J. Geoph Res: Earth Surface (2003-2012). 113(F1), F01002 (2008).

[3] H. Gao et al., "Using TRMM/TMI to Retrieve Surface Soil Moisture over the Southern United States from 1998 to 2002," J.Hydrometeorology. 7, 23 (2006).

[4] E. G. Njoku et al., "Soil moisture retrieval from AMSR-E," Ieee T. Geosci Remote Sens. 41(2), 215-229 (2003).

[5] Z. Bartalis et al., "Initial soil moisture retrievals from the METOP-A Advanced Scatterometer (ASCAT)," Geophys Res Lett. 34(20), 122-122 (2007).

[6] K. Scipal et al., "The global soil moisture archive 1992-2000 from ERS scatterometer data: first results," Geosci Remote Sens Symposium, 2002. IGARSS '02. 2002 Ieee Int. 1399-1401 (2002).

[7] S. Mecklenburg et al., "ESA's Soil Moisture and Ocean Salinity Mission: Mission Performance and Operations," Ieee T. Geosci Remote Sens. 50, 1354-1366 (2012).

[8] D. Entekhabi et al., "The Soil Moisture Active/Passive Mission (SMAP)," Geosci Remote Sens Symposium, 2008. IGARSS 2008. Ieee Int. 3(5), III-1-III-4 (2008).

[9] W. A. Dorigo et al., "Error characterisation of global active and passive microwave soil moisture datasets," Hydrology Earth Syst Sci. 14, 2605-2616 (2010).

[10]R. Parinussa et al., "An analytical solution to estimate the error structure of a global soil moisture data set," Ieee Geosci Remote Sens Lett. 8, 779-783 (2011).

[11]C. Albergel et al., "Evaluation of remotely sensed and modelled soil moisture products using global ground-based in situ observations," Remote Sens Environ. 118, 215-226 (2012). 
[12]E. G. Njoku, L. Li, "Retrieval of land surface parameters using passive microwave measurements at 6-18 GHz," Ieee T. Geosci Remote Sens. 37, 79-93 (1999).

[13]C. M. Taylor et al., "Afternoon rain more likely over drier soils," Nature. 489 (2012).

[14] Y. Y. Liu, R. M. Parinussa, and W. A. Dorigo, "Developing an improved soil moisture dataset by blending passive and active microwave satellite-based retrievals," Hydrology Earth Syst Sci. $15(2), 425-436(2011)$.

[15] Y. Y. Liu, W. A. Dorigo, and R. M. Parinussa, "Trend-preserving blending of passive and active microwave soil moisture retrievals," Remote Sens Environ. 123, 280-297 (2012).

[16] W. A. Dorigo et al., "Evaluating global trends (1988-2010) in harmonized multi-satellite surface soil moisture," Geophys Res Lett. 39(18), 143-157 (2012a).

[17]C. Albergel et al., "Monitoring multi-decadal satellite earth observation of soil moisture products through land surface reanalyses," Remote Sens Environ. 138, 77-89 (2013).

[18]R. An et al., "Validation of the ESA CCI soil moisture product in China," Int J Appl Earth Observation Geoinformation. 48, 28-36 (2016).

[19] W. A. Dorigo et al., "Evaluation of the ESA CCI soil moisture product using ground-based observations," Remote Sens Environ. 162, 380-395 (2015).

[20] J. Y. Zeng et al., "Evaluation of remotely sensed and reanalysis soil moisture products over the Tibetan Plateau using in-situ observations," Remote Sens Environ. 163, 91-110 (2015).

[21]R. L. Ray, J. M. Jacobs, and M. H. Cosh, "Landslide susceptibility mapping using downscaled AMSR-E soil moisture: A case study from Cleveland Corral, California, US," Remote Sens Environ. 114(11), 2624-2636 (2010).

[22]M. Piles, A. Camps, and M. Vall-Llossera, "Downscaling SMOS-derived soil moisture using MODIS visible/infrared data," Ieee T. Geosci Remote Sens. 49(9), 3156-3166 (2011).

[23]J. Kim, T. S. Hogue, "Improving Spatial Soil Moisture Representation Through Integration of AMSR-E and MODIS Products," Ieee T. Geosci Remote Sens. 50(2), 446-460 (2012). 
[24] O. Merlin et al., "Towards deterministic downscaling of SMOS soil moisture using MODIS derived soil evaporative efficiency," Remote Sens Environ. 112, 3935-3946 (2008).

[25] O. Merlin et al., "An improved algorithm for disaggregating microwave-derived soil moisture based on red, near-infrared and thermal-infrared data," Remote Sens Environ. 114, 2305-2316 (2010).

[26] A. K. Sahoo, J. M. Gabriëlle, and D. Lannoy, "Assimilation and downscaling of satellite observed soil moisture over the Little River Experimental Watershed in Georgia, USA," Adv Water Resour. 52, 19-33 (2013).

[27]S. Sánchez-Ruiz et al., "Combining SMOS with visible and near/shortwave/thermal infrared satellite data for high resolution soil moisture estimates," J.Hydrology. 516, 273-283 (2014).

[28] W. Zhao, A. N. Li, "A Downscaling Method for Improving the Spatial Resolution of AMSR-E Derived Soil Moisture Product Based on MSG-SEVIRI Data," Remote Sens. 5, 6790-6811 (2013).

[29] N. Djamai et al., "Disaggregation of SMOS soil moisture over the Canadian prairies," Remote Sens Environ. 170, 255-268 (2015b).

[30]N. Djamai et al., "A combination of DISPATCH downscaling algorithm with CLASS land surface scheme for soil moisture estimation at fine scale during cloudy days," Remote Sens Environ. 184, 1-14 (2016).

[31]L. Jiang, S. Islam, "An intercomparison of regional latent heat flux estimation using remote sensing data," Int. J. Remote Sens. 24, 2221-2236 (2003).

[32] J. Chen, "Validation of AMSR-E soil moisture products in northwest of China In Beijing," China: Chinese Academy of Meteorological Sciences. (2010).

[33] W. J. Zhang, "The observation and modeling on the distribution and change of the Chinese soil moisture data," Doctoral Dissertation, Meteorology, The Institute of Atmospheric Physics, Chinese Academy of Sciences. 2006. 
[34]M. X. Li, Z. G. Ma, and G. Y. Niu, "Modeling spatial and temporal variations in soil moisture in China," Chinese Sci Bull. 56(16), 1288-1300 (2011).

[35]T. N. Carlson, R. R. Gillies, and E. M. Perry, "A method to make use of thermal infrared temperature and NDVI measurements to infer soil water content and fractional vegetation cover," Remote Sens Rev. 52, 45-59 (1994).

[36]N. S. Chauhan, S. Miller, and P. Ardanuy, "Spaceborne soil moisture estimation at highresolution: Amicrowave-optical/IR synergistic approach," Int. J. Remote Sens. 24, 4599-4622 (2003).

[37]B. Fang, V. Lakshmi, "Soil moisture at watershed scale: Remote sensing techniques," J. Hydrol. $516,258-272(2014)$.

[38] Y. H. Kerr et al., "The SMOS mission: New tool for monitoring key elements of the global water cycle," Ieee T. Geosci Remote Sens. 98, 666-687 (2010).

[39] Y. H. Kerr et al., "The SMOS soil moisture retrieval algorithm," Ieee T. Geosci Remote Sens. 50, 1384-1403 (2012).

[40]H. H. Feng, Y. B. Liu, "Combined effects of precipitation and air temperature on soil moisture in different land covers in a humid basin," J. Hydrol. 531, 1129-1140 (2015).

[41]M. E. Hawley, T. J. Jackson, R. H. McCuen, "Surface soil moisture variation on small agricultural watersheds," J. Hydrol. 62(1), 179-200 (1983).

[42] D. L. Henninger, G. W. Petersen, and E. T. Engman, "Surface soil moisture within a watershedvariations, factors influencing, and relationship to surface runoff," Soil Sci Society Am J. 40(5), 773-776 (1976).

[43] J. Mcquigg, "A simple index of drought conditions," Weather wise. 7(3), 64-67 (1954).

[44] J. S. Famiglietti, J. W. Rudnicki, M. Rodell, "Variability in surface moisture content along a hillslope transect: Rattlesnake Hill, Texas," J. Hydrol. 210(1), 259-281 (1998).

[45]J. R. Kayla et al., "A method to downscale soil moisture to fine resolutions using topographic, vegetation, and soil data," Adv Water Resour. 76, 81-96 (2015). 
[46] G. Kim, A. P. Barros, "Space-time characterization of soil moisture from passive microwave remotely sensed imagery and ancillary data," Remote Sens Environ. 81, 393-403 (2002).

[47] N. X. Liang, "The impact of terrain on soil moisture and its effects small watershed scale," Master thesis, Northwest A \& F University. 2014.

[48] M. Temimi et al., "A combination of remote sensing data and topographic attributes for the spatial and temporal monitoring of soil wetness," J.Hydrol. 388, 28-40 (2010).

[49]M. Piles, A. Sánchez, "A microwave-optical/infrared disaggregation for improving spatial representation of soil moisture using AMSR-E and MODIS products," Washington, DC, 17-20 (2010).

[50]L. L. Zhang, Y. H. Zhao, and S. Yin, "Gradient analysis of dry valley of Minjiang River landscape pattern, based on moving window method," Acta Ecologica Sinica. 12, 3276-3284 (2014).

[51]Q. F. Pang, "Downscaling land surface temperature with a moving window approach," Master Thesis, University of Electronic Science and Technology of China. 2013.

[52]L. Brocca, S. Hasenauer, and T. Lacava, "Soil moisture estimation through ASCAT and AMSR-E sensors: An intercomparison and validation study across Europe," Remote Sens Environ. 115(12), 3390-3408 (2011).

[53] O. Merlin et al., "Performance Metrics for Soil Moisture Downscaling Methods: Application to DISPATCH Data in Central Morocco," Remote Sens. 7, 3783-3807 (2015); doi:10.3390/rs70403783.

[54]W. A. Dorigo et al., "Constructing and analyzing a 32-years climate data record of remotely sensed soil moisture," Ieee T. Geosci Remote Sens Symposium (Igarss). 2028-2031 (2012b).

[55]Z. Wang, "Accuracy verification and improvement of global microwave soil moisture product CCI in China," Master Thesis, Geography, Hohai University. (2014).

[56] Y. H. Ran, X. Li, and L. Lu, "China Land Cover Classification at $1 \mathrm{~km}$ Spatial Resolution Based on a Multi-source Data Fusion Approach," Adv Earth Sci. 24(2), 192-203 (2006). 
[57]Y. H. Ran et al., "Large-scale land cover mapping with the integration of multi-source information based on the Dempster-Shafer theory," Int. J. Geogr Inf. Sci. 26(1), 169-191 (2012). Version 1.0. 26 November 2012. satellite imagery over land. Remote Sensing. 4, 3287-3319(2012).

180

181 
200 Fig. 1 Study area and locations of the ground-based validation sites used in this study.

201 Fig. 2 An overview of the active and passive sensors that provide the ECV_SM product. ${ }^{\mathbf{5 4}}$

202 Fig. 3 Distribution of soil moisture of ECV_SM and downscaled one at first ten days of October in 2010: (a) original ECV_SM; (b) ECV_SM downscaled.

Fig. 4 Correlation between the in situ values of soil moisture and the down-scaled one in four land use and land cover types at: (a) Dingxi（Grasslands，29 data pairs ) ;

(b) Fuxing (urban and built-up lands, 91 data

(d) Youyu (Farmland, 66 data pairs). 
227 Hui-Lin Wang graduated from Wuhan Technical University of Surveying and Mapping in 1984. $\mathrm{He}$ is currently a senior engineer at the Department of Geography Information Science, School of Geographic and Oceanographic Sciences, Nanjing University. He engages in research and teaching in the fields of Photogrammetric, Remote Sensing, Surveying, Mapping and Global Position System (GPS). His research interests now include remote sensing image processing, soil moisture downscaling and fusion and grassland ecological environment monitoring.

Ru An received her $\mathrm{BS}$ and $\mathrm{PhD}$ degrees in cartography and geographic information systems from Nanjing University, China, in 1984 and 2005, respectively. Since 2001, she has been teaching at Hohai University. She has served as a professor since 2007. Her research interests include remote sensing image matching, processing and analysis; monitoring grassland ecological environment by remote sensing; and soil moisture evaluation, downscaling and fusion.

Jiajun You received his MSc degrees in Geography from Hohai University, China in 2015. His current research interest is improvement of soil moisture products.

Ying Wang is a PhD student in Geography and environment, University of Southampton, UK. She received her Master degree in urban planning form Nanjing University, China, in 2015. Her research interests include human behavior, environmental change and urban governance with the help of geographic information technology.

Yue-Hong Chen received his BS degree from Hohai University, Nanjing, China in 2010, his MSc and $\mathrm{PhD}$ degrees from the Institute of Geographical Sciences and Natural Resources 
Research, University of Chinese Academy of Sciences, Beijing, China in 2013 and 2016, respectively. His research interests include remote-sensing image processing and super resolution mapping.

Xiaoji Shen received his BS and MSc degrees in GIS from Hohai University, China in 2014 and 2017 respectively. He is going to pursue a PhD degree in Monash University, Australia. His current research interests include soil moisture microwave remote sensing and change detection of vegetation.

Wei Gao received his MSc degree in Geography from Hohai University, China in 2017. His current research interest is vegetation remote sensing.

Yinan Wang is pursuing his MSc degrees in Geography from Hohai University, China. His current research interest is improvement of soil moisture products.

Yu Zhang is pursuing her MSc degrees in Geography from Hohai University, China. Her current research interest is vegetation remote sensing.

Zhe Wang recieved her MSc degree in Cartography and Geographic Information System from Hohai University, China in 2014. Her current research interest is evaluation of soil moisture products.

Jonathan Arthur Quaye-Ballard received his $\mathrm{PhD}$ in Geodesy and Survey Engineering from Hohai University, Nanijing, China in 2015. He is a Senior Lecturer at Kwame Nkrumah University of Science and Technology, Ghana. His current research interests lie in the application of Geo-information in droughts/floods, sanitation, mapping, poverty alleviation, sustainable agriculture and precise vegetation monitoring, global data validation; Systems Analysis, Usability Testing; and Computer Supported Collaborative Learning. 